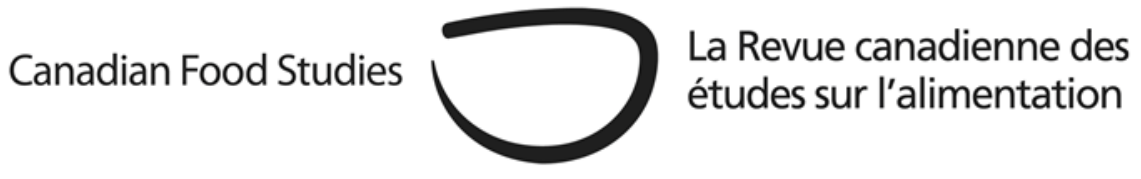

Book Review

\title{
Mind your Ps, ask your Qs: A review of The King's Peas by Meredith Chilton
}

\section{Gardiner Museum / Arnoldsche Art Publishers, 2019, 144 pages}

[For more about Savour: Food Culture in the Age of Enlightenment, see Jennifer O'Connor's exhibition review in this issue.]

Review by David Szanto*

It is difficult not to like The King's Peas, the genteelly designed and generously produced 'cookbook' published as companion to the Gardiner Museum's 2019-20 exhibition, Savour: Food Culture in the Age of Enlightenment. At the same time, however, it is also rather hard to like it uncritically, largely because of the celebration of power and colonialism that it represents.

Focusing on the evolution in foodish taste and practice that took place between the midseventeenth century and the French Revolution, The King's Peas juxtaposes historical recipes, citations, and anecdotes with copious colour images of some of the fascinating and extravagant works that were on display within Savour. These include prints and paintings, silver- and glassware, numerous ceramic pieces, and a few contemporary knitted objects. Quotations from food writers of the period dot the text, including culinary exhortations from such authors as Hannah Glasse, Menon, Elizabeth Raffald, and François de la Varenne. Following an introduction by Gardiner curator emerita, Meredith Chilton, the book is divided into relatively conventional recipe categories. Somewhat out of place - and perhaps intended to add a little star power-are four culinary contributions from the executive chef of Toronto's York Club, Markus Bestig.

The producers of this book, like the exhibition curators, have positioned their offering as both historical-cultural assemblage and insight into current foodways. They draw attention to the concerns of the time - culinary and agricultural innovation, local and seasonal consumption, healthful and flavourful eating — noting that these are also present within many contemporary foodscapes. As intriguing a parallel as this may be, they also too easily skip over some rather glaring issues that link the Age of Enlightenment with the Age of the Anthropocene: a profound 
stratification of socioeconomic privilege, the exploitation of natural resources, the assumption of 'common' concerns among eaters, and the problematic power relations that characterize many regions' food systems. By glorifying (and universalizing) “our modern dining culture," the book seems to evade the issue that "we" are heterogeneous, and that so-called fine dining is tightly coupled with French, English, and Italian histories of colonialism.

At the same time, The King's Peas is a remarkable achievement in historical documentation. The tableware and other pieces that are depicted - tureens, dishes, crystal, gravy boats, dessert moulds, and several trompe l'oeil artworks - reveal the aesthetics and values of the wealthy classes of the time. As Jennifer O'Connor points out in her review of the Savour exhibition (this issue), the Enlightenment was characterized by a valorization of human reasoning and an attention to the everyday within art and craft. Indeed, many of the images shown are quite visually humble, even as an extreme attention to detail and production quality are revealed. Nonetheless, several opulent pieces of silverware point to a tension between embellishment and plainness, echoed also in the included texts about the intentionality within French and English cookery.

Several notable images and passages add historical intrigue and prompt reflection for readers. One visual, "A Table, showing at one View, the proper Seasons for Sea Fish," lists twenty-seven piscine varieties and the months in which they should be caught. Such indications (this one from the book, English Housewifery, by cookery writer Elizabeth Moxon), were generally directed at the (literate) cooks and senior servants of upper-class households, like many works of food-related advice from the period. Notably, while today's Ocean Wise iPhone app may confer similar information, its context, motivation, and audience are very different. Later, a brief text titled The Agonies of Carving Turkey includes details about the French naming of the bird, the importance of knife technique (for "gentlemen"), and a snippet from Giacomo Casanova's memoir about a moment of carving shame. It, too, evokes contemporary connections - in this case, memories of family dinners and the often-fraught dynamics among posturing menfolk. Another image, depicting an ornate, marine-themed "pickle stand"accompanied by an explanation of the late-1700s fashion for eating pickled vegetables - suggests that the recent lactofermentation resurgence among hipster-foodists has long-past historical echoes.

The bulk of the book is dedicated to adaptations of historic recipes, thirty-two in all, divided into sections on soups, eggs and cheese, vegetables, meat, sauces, and sweets. They range from such familiar dishes as butternut squash soup (including the amusingly modern use of kosher salt and an immersion blender) and chicken with cream and mushrooms, to more unusual offerings, such as "Bacchus Sauce" (with white wine, garlic, and beef stock) and brown-bread ice cream. The titular "King's Peas" brings together frozen peas (!) with heavy cream and a bouquet of fresh herbs. Again, tensions aplenty are represented between access and affordability, effort and convenience, eurocentrism and multiculturality. Occasional anecdotes expose some of the sociocultural and political inequities of the time: Caravaggio's violent mistreatment of a waiter; John Evelyn's advocacy of a less meat-centric diet; and the miserable relationship 
between sugar consumption and slavery. While these take a partial step toward balancing the adulation of the Enlightenment, they are too slim to add criticality and thus tend to the tokenistic.

Clearly not every cookbook needs to (or can) address the colonialist violence, oppression, and exploitation with which contemporary food and food systems are imbued. Equally evident is that The King's Peas is not really intended as a day-to-day cookbook. Its horizontal format, highquality paper and printing, and juxtaposition of few recipes with much complementary material all place it on a pile with many other coffee-table cookbooks, rather than on the kitchen counter. Instead, it is a loving celebration of a very specific slice of gastronomic history. What makes this troubling, however - and key to the tension that makes the book hard to like-is that it traces "our" current foodways back to this history without more fully explicating the deep injustices of those times and places. Moreover, and particularly in a place like Turtle Island/North America, overestimating the influence of this history on what is produced, cooked, and eaten in the here and now tends to reinforce the erasures that colonial culture has already wrought. Given the important efforts that food scholars are making towards undoing this damage, and towards seeking innovative, resilient, and equitable paths forward, it would be nice to see future curators and authors of historical food content make more of a contribution to changing our perceptions and future actions, rather than shoring up a problematic vision of the past.

David Szanto is a teacher, researcher, and artist, taking an experimental approach to food and food systems through design, ecology, and performance. Having previously taught at Concordia University, l'Université du Québec à Montréal, and the University of Gastronomic Sciences in Italy, he is currently a part-time faculty member at l'Université d'Ottawa. 